\title{
New Trends of Intelligent E-Marketing and Consumer Buying Behaviour: A Study of Selected Universities in Osun State, Nigeria
}

\author{
Haorayau Bolaji Babalola ${ }^{1}$, Saheed Ademola Lateef ${ }^{2}$, Abu Zekeri (PhD) ${ }^{3}$ \\ ${ }^{1}$ Osun State University \\ ${ }^{2}$ University Sultan Zainal Abidin (UniSZA) \\ ${ }^{3}$ Kwara State University Malete, Nigeria \\ mobolajiige07@yahoo.com \\ latsad4real@yahoo.com \\ zekeriabu2007@yahoo.com
}

\begin{tabular}{ll}
\hline \multicolumn{2}{l}{ ARTICLE DETAILS } \\
\hline History & : August \\
Received & Revised Format $:$ September \\
Accepted $\quad$ October \\
\hline
\end{tabular}

Keywords :

E-marketing, consumer-buying behavior, technology, e-mail marketing, mobile marketing, Nigeria

\begin{abstract}
S
Understanding the attitude and behavior of customers is essential for every company where consumers differ in attitudes towards product/service. The consumer buying behavior in today's information-saturated world is based on how a product/service is marketed. However, the rapid diffusion of technology anchored growth and challenges on e-marketing trends. For instance, despite the widespread and large-scale adoption of e-marketing around the world, one does not see this trend happening on a big scale in Nigeria. Therefore, this study examines the influence of e-marketing factors on consumer buying behavior in the Nigerian context with particular reference to the University students participating in online business. The study employed the quantitative method, where primary data were collected via online distribution of the questionnaires among 233 customers, specifically students of the Osun state Universities in Nigeria. Also, structural equation modeling using AMOS software was employed to examine the relationship and hypothesis testing. The findings of this study revealed that e-marketing is positively and significantly influence consumer buying behavior in the area of e-mail marketing, mobile marketing, and eadvertising factors. The study asserted that firms must engage the consumers using technology that are more likely acceptable by consumers in the present digital and customer-oriented era. Also, knowing fully the emerging technologies may furnish valuable insights for various stakeholders to work well in Nigeria. Finally, the new trends in e-marketing are recommended from a strategic and operational level in which different techniques ease the buying behavior of consumers
\end{abstract}

C2020 STIM Lasharan Jaya Makassar

\section{INTRODUCTION}

As the world becomes a global village due to the internet revolution, electronic marketing has become the most interesting and important aspect of the explosion that changed the way businesses operate (Waheed \& Jianhua, 2018). The widespread of electronic adoption among consumers resulted in opportunities for the firms to communicate their products and services information in a fast and reliable way (Persual \& Azhar, 2012; Waheed et al., 2017). Also, several academicians and practitioners realized that it is difficult for firms to ignore the applications of technologies in today's' business operation to survive and gain success. Thereby, the majority of the business organization now offer goods \& services as well as communicate with their suppliers and buyers over the internet (Waheed, Yang \&Jianhua, 2017; Arifin \& Frmanzah, 2015). This has brought about a highly competitive market. As a result large brickand-mortar, companies are rethinking their business models intending to stay competitive. A report by Digital economy (2017) says that over 1 trillion dollars in revenue were generated by 
e-marketing worldwide. The Internet has changed the whole concept and view of marketing. Its growth is highly effective in the overall world economy, in which different names were given online marketing. This includes e-shopping, e-store, e-web stores, and internet shops among others. (Ashwini \& Manjula, 2016).

Meanwhile, Nigeria is not exempted from this growing phenomenon. Many businesses in the country now strive to replicate those online dealings and transaction patterns which their counterpart abroad practice. However, infrastructural deficiencies have impeded the development of digitalization in the Nation's body polity but satisfactory signals are emerging that the government intends to actively promote and support the required and relevant structures (Nwokah \& Irimagha, 2017; Ajiboye, Ogunrinade, \& Ayanleke, 2018). Despite the important role that businesses play in the global economy and the potential benefits of e-Marketing, the level of e-marketing adoption among Nigerian companies is low. Also, there is a lack of empirical evidence regarding the use of e-marketing in small and medium enterprises (SME's) business in Nigeria (Kalu, Nto, \&Nwadighoha, 2017). These issues mentioned above make the e-marketing application a very difficult task in the business environment.

In the same way, Nigerian businesses are not reaping maximum benefits from their investment in e-marketing as several organizations adopt internet-based promotional methods to appeal to a target market by spending a massive budget (Ajiboye et al., 2018). The study on mastery of e-advertising is low and therefore unable to generate customer satisfaction. According to Brodie et al. (2007), advertising helps deliver information on particular products/services to attain consumers' attention efficiently, while advertising via the internet is becoming almost the priority of many practitioners for the dissemination of information. However, E-advertising has not encouraged enough customer patronage in many firms in Nigeria (Ogundele et al., 2013). Several times, internet services are poor and many firms have difficulties in transacting or making payments on time. This has contributed to low satisfaction and resulted in a lot of complaints from customers. Many SME's businesses do not encourage e-payment due to poor understanding and drive to go online (Kalu, Nto\&Nwadighoha, 2017). As a result, many consumers who do not do cash transactions are handicapped and this has affected the level of patronage as well.

Moreover, as the integration of technology advancement is critical for the business to achieve efficiency, several researchers have the opinion that more study needed on e-marketing and consumer buying behavior. Primarily empirical evidence is required across the world which should be conducted on business to customers; business to business and business to government (Waheed et al., 2017; El-Gohary, 2012). Meanwhile, many studies have been carried out the empirical investigation on various electronic marketing promotions medium. This includes email marketing (Waheed \& Jianhua, 2018; Scharl et al., 2005); e-advertising marketing (Hooda \& Aggarwal, 2012); mobile marketing (Bauer et al., 2005); e-payment marketing (Chin \& Ahmad, 2015; Adebayo et al., 2017). However, the relationship of e-marketing in the area of customer behavior is not well researched in Africa, especially in Nigeria. Therefore, the objective of this study is to establish the extent businesses in Nigeria use electronic marketing and also examine the relationship between e-marketing dimensions on consumer buying behavior in Nigeria with the study of University students in Osun state. Whereas, the specific objectives are as follows:

1. To examine the impact of e-mail marketing on consumer buying behavior of University students in Osun state.

2. To determine the influence of e-advertising marketing on consumer buying behavior of University students in Osun state.

3. To examine the relationship between mobile marketing on consumer buying behavior of University students in Osun state.

4. To examine the impact of e-payment marketing on consumer buying behavior of University students in Osun state. 


\section{LITERATURE REVIEW}

According to Kotler and Armstrong (2012), consumer behavior is the buying behavior of final consumer's individuals and households that buy goods and services for personal consumption. Grimsley (2015), states that consumer buying behavior is the total of a consumer's attitudes, preferences, intentions, and decisions regarding the consumer's behavior in the market place when purchasing a product (goods) or service. Several practitioners and academicians' opinion that consumer buying behavior is enormously focused on the area of marketing management (Constantinides,2004). Accordingly, consumer behavior is related to the attitude, preferences, intention, and decision making of the consumers towards particular products/services (ElGohary \& Kotabe, 2001). Meanwhile, several factors were referred to as affecting consumer buying behaviors. This includes but is not limited to family and friends, peer groups, brand name, and product quality. Aside from that, consumer behavior is based on a complete process that includes information search, recognition of product and services, purchase decision, and post-purchase assessment decision. Furthermore, consumer buying behavior is a behavioral, cognitive, and process that is involved in high degree items (Kotabe, 2009). Nevertheless, technologies have played a crucial role in marketing practices including electronic marketing (Kotabe et al., 2007).

From the prior survey study, it has been revealed that little research studies available on electronic marketing in Nigeria. Most especially, the empirical linkage is not widely studied in marketing practices (Kotabe et al., 2007). Also, research on electronic marketing is a new phenomenon in African countries. As stated by (Farley et al., 2005), the positive relationship between electronic marketing and marketing practices as carried out in the USA market. Also, it is a source of competitive advantage. This means that the adoption of electronic marketing is positively correlated with a firm's performance. Kotabe et al. (2007) revealed that the integration of electronic marketing with other marketing practices might improve organizational performance along with a competitive edge. Thus, electronic marketing plays a dramatic impact to capture the consumers' attention around the world (Loane et al., 2004). Meanwhile, several kinds of literature have been investigated the effect of advertising tools along with emerging advertising trends through the internet. This includes electronic mail marketing, e-advertising marketing, mobile marketing, e-payment, database and network, intranet/extranet marketing, collaboration marketing, and direct marketing (Coviello, 2001; El-Gohary, 2012). Thus, the intention of this study focuses on only four dimensions of the e-marketing dimension towards consumer buying behaviors as recommended from the previous studies. These are electronic mail marketing, e-advertising marketing, mobile marketing, and e-payment. Based on this assumption, the study hypothesizes in the following sub-sections.

\subsection{E-mail marketing and Consumer Buying Behavior}

E-mail Marketing is defined as a channel of communication via the internet to disseminate product/services information to the target audience (Sterne \& Priore, 2000). Electronic mail marketing has become the leading strategy of information dissemination. As stated by Tamlinson (2009), computer engineers achieved the first electronic mail testing in the year 1971 and after which electronic mail becomes an important medium of business operation and maintaining customer relationships since the 1990s (Pavlov et al., 2008; McCloskey, 2006). Email marketing also ensures a higher return in investment (Bawm\& Nath, 2014). This was claimed by Pavlov et al. (2008) advertisement using electronic mails can facilitate establishing a long-term relationship with different consumers efficiently and effectively. As recommended by Bawm and Nath (2014), e-mail marketing happened to be the most trusted and reliable medium of communication. To the extent that nowadays, marketing via e-mail is widely growing due to extensive usage and almost more than 2.8 billion people are e-mail users around the world. Also, electronic marketing is a timely and cost-effective medium that supported 
advertisers to share product information (Cases et al., 2010; Waheed et al., 2017). However, scholars have recommended that more studies needed to be conducted to examine the linkage of e-mail marketing and consumer buying behavior (Mullen \& Daniels, 2011; Waheed\&Jianhua, 2018). In this regard, e-mail marketing can perform an important impact to reinforce consumer buying behavior. The study hypothesizes has the following:

H1 There is a significant relationship between e-mail marketing and consumer buying behavior.

\subsection{Mobile Marketing and Consumer Buying Behavior}

Mobile Marketing is defined as an advertising medium via smartphones, mobile phones, and other electronic gadgets together with many features. This includes short message services, multimedia messaging, mobile apps, wireless application protocol among others (Persaud\&Azhar, 2012; Smulkupt et al., 2010). Also, mobile marketing is efficient marketing tools that produce more chances for the firms to communicate products/services message anywhere, anytime and in a wider range (Lee et al., 2017; Chang et al., 2009). However, several scholars have argued that study on mobile marketing is still on the elementary stage and future work is explicitly needed, particularly empirical linkage around the world (El-Gohary, 2012; Smutkupt et al., 2010); such researchers have suggested that all attributes of mobile devices empower the promotional campaigns by reach consumers directly via their smartphones and rest of e-gadgets. Thus, based on the suggestion of experts that future linkage can be examined due to the extensive utilization of mobile devices and promotional campaign via such methods can perform a dynamic role to reinforce consumer buying behaviors. Hence, the study formed the hypothesis as follows:

H2 There is a significant relationship between mobile marketing and consumer buying behavior.

\subsection{E-advertising and Consumer Buying Behavior}

According to Aslam and Karjaluoto (2017). E-advertising is a form of promotion that uses the internet and the World Wide Web for the expressed purpose of delivering marketing messages to attract customers. These e-advertising tools include contextual ads on search engine results pages, banner ads, Rich Media Ads, Social network advertising, online classified advertising, advertising networks, and e-mail marketing, including e-mail spam (Chandoriya, 2016; agyare, 2019). These directories complement television advertising and allow the view of the commercials of some brands. However, the inclination of people towards online advertising in Nigeria is also in its infancy period (George \& Education, 2019; Edoumiekumo, 2017). The people are somewhat reluctant to buy things online due to the increasing trend of online frauds and the websites could not be trusted fully.

Several studies carried out in the past have proven that the average man watches over 40,000 commercial ads in a year which is quite many. Nevertheless, e-advertising strategies like popups, banners, and pop-under are annoying to internet users (Dehwal, 2016). Many scholars stated that online consumers are more goal-oriented and judge e-advertising even more harshly than those in the other media (Hamdi\&Khemakhem, 2019a; Agyare, 2019; Deshwal, 2016). Thus, the negative intentions develop by users towards intrusive ads resulted in than to not return to that website. The survey by Jupiter Research indicated that $69 \%$ of users consider popups annoying. Also, $23 \%$ have the intention of not return to the site simply due to the ads (Dehwal, 2016; McElfresh et al., 2007). With users feeling for instant gratification not being able to achieve their aim and objective while online is beginning to diminish their feelings towards advert method, website environment, and firm's brands. Meanwhile, Dehwal (2016); Bhakar et al. (2019); Chandoriya (2016) revealed the positive significant relationship between e-advertising and consumer buying behavior. Based on the prior studies review on the linkage of e-advertising and consumer buying behavior above, the study formed hypothesis as follows:

H3 There is a significant relationship between e-advertising and consumer buying behavior. 


\subsection{E-payment and Consumer Buying Behavior}

E-payment refers to paying for goods or services on the internet. It includes all financial operations using electronic devices, such as computers, smartphones, or tablets (Xena \& Rahadi, 2019; Agarwal, 2019; Chin \& Ahmad, 2015). This electronic payment includes ATM, Web payment, E-POS, Mobile banking payment system, NIBSS, third party cheques, bank draft, and other instruments. The emergence of development in technology for financial transactions has increasingly fueled the adoption and use of e-payment instruments worldwide (Adebayo et al., 2017). Several studies have predicted the emergence of an electronic-based payment economy where the traditional money made up of paper and coins replaced with electronic means for the basic transaction (Adebayo et al., 2017; Princewell \& Anuforo, 2013; Zeithaml \& Gilly, 2017). However, Nigeria is cash dominated economy. Most transactions in the country are cash-based and most Nigerians love it that way. According to this class of people, cash is safe and more convenient as it is generally accepted. Some consumers are afraid of electronic payment because they fear their money will be stolen online (Sheikh, Shahzad, \& $\mathrm{Ku}$ Ishak, 2017). They often recount how their money or those of their friend or family were stolen via ATM. To make online shopping a way of life in Nigeria, Nigerian consumers must be open to making payments with e-payment solutions. Status Quo also related to the low acceptability of e-payment solutions in Nigeria. Nigerians are often skeptical about new things, especially when money is involved. Each time government introduces a new policy, people line-up tons of excuses why that policy could be bad for the country and how it could break Nigeria into tiny little pieces (Sheikh, Shahzad, \& Ku Ishak, 2017). Making excuses for the status quo is now a natural pastime of some Nigerians. It is because of this attitude that the cashless policy introduced in Nigeria is having some fundamental problems. Thus, many studies revealed the association between e-payment and consumer buying behavior (Adebayo et al., 2017; Xena \& Rahadi, 2019; Agarwal, 2019; Chin \&Ahmad, 2015). Based on the prior studies shown the relevance of examining the linkage of e-payment and consumer buying behavior above, the study formed hypothesis as follows:

H4 There is a significant 23 dht4 relationship between e-payment and consumer buying behavior.

\section{RESEARCH METHODOLOGY}

This study examines the relationship between electronic marketing and consumer buying behavior of Osun State Universities Students in Nigeria. The study looks at the e-marketing in the area of e-mail marketing, mobile marketing, e-advertising, and e-payment. Using a positivist research attitude; this study is based on primary data sources, quantitative in nature, and has a deductive research approach. It is a cross-sectional study, and data were collected using questionnaires. Figure 1 below indicated the research framework of the relationship between electronic marketing and consumer buying behavior.

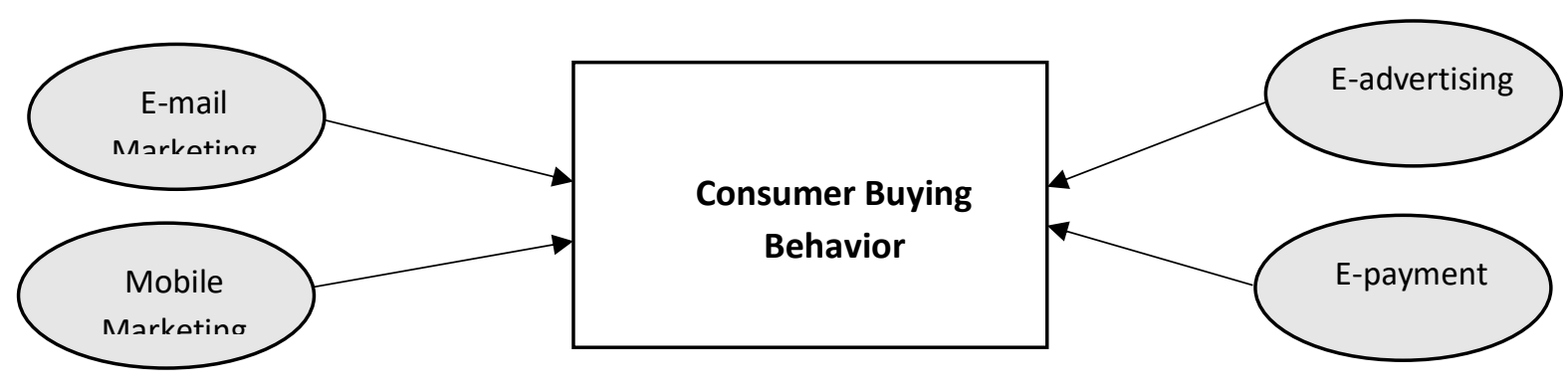

Figure 1: Research Framework 
According to Martin and Guerin (2006), research methodology was grounded on the summary of the systematic investigation, procedure, sample selection, and analysis, which were carried out in the research. Hence, the main purpose of this study is to examine the effect of using electronic marketing on consumer buying behavior of Osun State University Students in Nigeria, questionnaire was developed to collect data from both postgraduate and undergraduate students at Osun State University in Nigeria. The survey questionnaire consisted of two parts which include demographic information based on five attributes. The second part was based on the main constructs of the relationships among the e-marketing and consumers' buying behavior comprised of 32 statements. Primary data were collected by distributing questionnaires after the pilot test and sampling techniques were expressed.

Respondents were asked to assess the items of different variables such as e-mail marketing, mobile marketing, e-advertising, and e-payment and consumer buying behavior based on 5point Likert scales that range from strongly disagree (SD: 1) to strongly agree (SA: 5). Therefore, this study distributed 376 questionnaires to target respondents via an online google survey to students at Osun State University after determining the sample size from the entire population. Online surveys (Survey monkey) are perceived as more salient, exciting, and entertaining than traditional surveys by respondents who are experienced in using the internet (Evans \& Mathur, 2005), as in this case, where all the respondents were online shoppers. Both descriptive and inferential analyses were used to examine the effect of the stated variables (Hair et al., 2014). The survey research makes use of the fundamental information and CB-SEM (AMOS Software) that carried out to analyze the relationship among the constructs which influence electronic marketing on consumer buying behavior of both postgraduate and undergraduate students in Osun State Universities in Nigeria.

Structural Equation Modelling (SEM) was employed for data analysis method through AMOS statistical software based on the parametric SEM in AMOS 22.0 (Awang, et al., 2019). The analysis model is comprised of the measurement model and the structural model. In the measurement model, validity (convergent, construct, and discriminant) and reliability (composite reliability) of the constructs were analyzed through confirmatory factor analysis (CFA). Once the reliability and validity of the measurement model were achieved, the structural model was used for empirical hypotheses testing in the study.

\section{RESULTS}

Out of 376 questionnaires distributed to the undergraduate and postgraduate study of Osun State University, 233 questionnaires were returned representing a $62 \%$ response rate. 8 cases of questionnaires were excluded due to the issue of outliers (both univariate and multivariate outliers). Finally, 225 (60\%) questionnaires were retained for further analysis. Meanwhile, confirmatory Factor Analysis (CFA) validates the instrument by assessing the constructs in terms of reliability, validity, and uni-dimensionality (Raza \&Awang, 2020; Awang et al., 2015; Saunders \& Lewis, 2012). Having done with the exploratory factor analysis (EFA) procedure, the field study was carried out using a set of construct items. Any factor loading below the rule of thumb was removed and objects were assembled into their relevant components. Furthermore, the field study data were used to validate the construct's measurement model. Considering CFA, the reliability of instruments is primarily examined using composite reliability (CR) index, while construct validity that happens to be the key validity measure in CFA is comprised of convergent and discriminant validity (Raza \&Awang, 2020).

The survey instruments adopted in this study comprises of one exogenous construct with four dimensions and one endogenous constructs. The e-marketing (e-mail marketing, mobile marketing, e-payment, and e-advertising) is considered as an exogenous construct and consumer buying behavior is endogenous constructs. Thus, Table 3 indicated the result of the measurement model where the convergence validity and composite reliability were evaluated. The result indicates the value of factor loading, AVE, and composite reliability where the result of this study shown the adequate factor loadings of all items (above the threshold value of 0.6) except for three items that were excluded due to low factor loading. As indicated in Table 4: 
Table 4: Summary of the Measurement Model (Construct Validity and Indicator Reliability)

\begin{tabular}{|c|c|c|c|c|}
\hline Constructs & Items & $\begin{array}{c}\text { Factor } \\
\text { Loading }\end{array}$ & CR $(>0.6)$ & AVE $(>0.5)$ \\
\hline \multirow{7}{*}{ E-mail Marketing } & EM1 & 0.82 & 0.920 & 0.639 \\
\hline & EM2 & 0.92 & & \\
\hline & EM3 & 0.86 & & \\
\hline & EM4 & 0.85 & & \\
\hline & EM5 & 0.95 & & \\
\hline & EM6 & 0.65 & & \\
\hline & EM7 & 0.56 & & \\
\hline \multirow{6}{*}{ Mobile Marketing } & MM1 & 0.96 & 0.865 & 0.573 \\
\hline & MM2 & 0.92 & & \\
\hline & MM3 & 0.55 & & \\
\hline & MM4 & 0.60 & & \\
\hline & MM5 & 0.66 & & \\
\hline & MM6 & 0.61 & & \\
\hline \multirow[t]{6}{*}{ E-Advertising } & EA1 & 0.73 & 0.804 & 0.515 \\
\hline & EA2 & 0.61 & & \\
\hline & EA3 & 0.94 & & \\
\hline & EA4 & 0.93 & & \\
\hline & EA5 & 0.86 & & \\
\hline & EA6 & 0.76 & & \\
\hline \multirow[t]{7}{*}{ E-Payment } & EP1 & 0.79 & 0.839 & 0.516 \\
\hline & EP2 & 0.67 & & \\
\hline & EP3 & 0.92 & & \\
\hline & EP4 & 0.71 & & \\
\hline & EP5 & 0.82 & & \\
\hline & EP6 & 0.90 & & \\
\hline & EP7 & 0.72 & & \\
\hline \multirow[t]{8}{*}{ Consumer Buying Behavior } & CBB1 & 0.66 & 0.839 & 0.516 \\
\hline & CBB2 & 0.77 & & \\
\hline & CBB3 & 0.92 & & \\
\hline & CBB4 & 0.87 & & \\
\hline & CBB5 & 0.87 & & \\
\hline & CBB6 & 0.80 & & \\
\hline & CBB7 & 0.68 & & \\
\hline & CBB8 & 0.85 & & \\
\hline
\end{tabular}

In the Confirmatory Factor Analysis (CFA) results, the report is indicated that the model was acceptable for further analysis. CFA results indicate that the RMSEA $=.075, \mathrm{GFI}=.890$, CFI $=.895, \mathrm{TLI}=.911, \mathrm{NFI}=.852$, and $\chi 2 / \mathrm{df}=3.126$. Only GFI and $\chi 2 / \mathrm{df}$ met the required level, but other indicators failed to attain the minimum level. These results indicated that the absolute fit index and incremental index for the pooled constructs meet the required level, which shows the attainment of model fit indices. To accomplish fitness indices, certain modifications were needed in the model. Through CFA, the instrument was recognized as valid and reliable and could be used for hypotheses testing. The result reported in Table 5 below:

Table 5: Model Fits (After deleting low factor loading items)

\begin{tabular}{lllll}
\hline S/N & Name of Category & Index Value & Threshold & Remarked \\
\hline 1 & Absolute fit & $R M S E A=.075$ & RMSEA $<.08$ & The required level is achieved \\
& & $G F I=.890$ & $G F I>.90$ & The required level is achieved \\
\hline 2 & Incremental fit & $C F I=.895$ & $C F I>.90$ & The required level is achieved \\
& $T L I=.911$ & $T L I>.95$ & The required level is achieved \\
& $N F I=.852$ & $N F I<.90$ & The required level is achieved \\
\hline 3 & Parsimonious fit & $X^{2} / d f=3.126$ & $X^{2} / d f<5$ & The required level is achieved \\
\hline
\end{tabular}




\section{Assessment of the Structural model}

Figure 2 has presented the structural model which reveals the causal effects of e-marketing constructs on consumer buying behavior construct. It was found that the proposed model explained a highly significant percentage of the variance in consumer buying behavior (54\%). Cohen (1988) claims that R2 exceeding $26 \%$ is considered to have a large effect in a causal model. Therefore, the current model that involved evaluating the level of e-marketing is meaningful and sufficient since it contributes a high impact on the research on consumer buying behavior. The result of the structural model indicated in Figure 2 and Table 6:

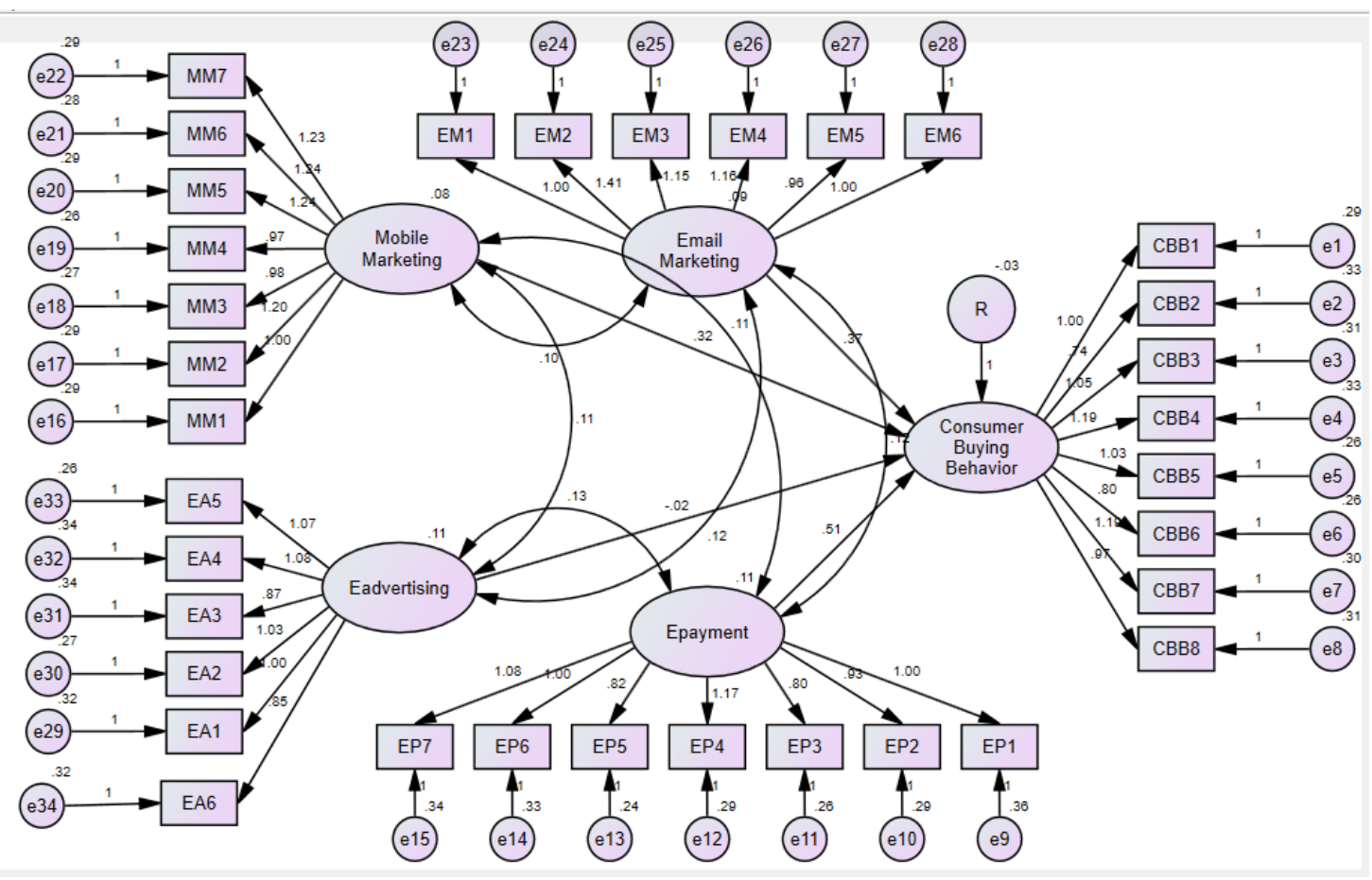

Figure 2: Assessment of the Structural Model

Table 6: Result of the Structural Model (Testing of Hypotheses)

\begin{tabular}{l|l|l|r|r|r|c}
\hline Hypothesis & & & Estimate & S.E. & C.R. & P \\
\hline Consumer Buying Behavior & $<---$ & Email Marketing & .369 & .083 & 4.428 & $* * *$ \\
Consumer Buying Behavior & $<---$ & Mobile Marketing & .324 & .113 & 2.874 & .004 \\
Consumer Buying Behavior & $<---$ & E-advertising & .506 & .175 & 2.899 & .004 \\
Consumer Buying Behavior & $<---$ & E-payment & -.016 & .144 & -.112 & .911 \\
\hline
\end{tabular}

The phase of hypotheses testing was done using structural equation modeling after the validating of the measurement model. The study tests the significant relationship between emarketing and consumer buying behavior in Osun State Universities with four sub-hypotheses (e-mail marketing, mobile marketing, e-payment, and e-advertising). Table 6 shows the path coefficients, standard error, and p-values of the relationship between constructs presented in the consumer buying behavior model. Findings, presented in Table 6 , supported H1 ( $\beta=.369$, SE $=.083, \mathrm{p}=.000<.01)$, which stated that there was a significant and positive effect of e-mail marketing on consumer buying behavior. Findings also supported $\mathrm{H} 2(\beta=.324, \mathrm{SE}=.113, \mathrm{p}=$ $.004<.01)$, which concluded that there was a significant and positive effect of mobile marketing on consumer buying behavior. Likewise, Findings also supported $\mathrm{H} 3(\beta=.506, \mathrm{SE}=.175, \mathrm{p}=$ $.004<.01$ ), which concluded that there was a significant and positive effect of e-advertising on consumer buying behavior. However, results were not supported H4 $(\beta=-.016, \mathrm{SE}=.144, \mathrm{p}=$ 
$-.147>.05$ ), which was interpreted as e-payment having insignificant effect on consumer buying behaviour. The overall result of the study indicates that e-marketing has a significant influence on consumer buying behavior in the area of e-mail marketing, mobile marketing, and e-advertising. Thus, creating an enabling environment for online customers by making provision for an adequate marketing platform will eventually boost the buying behavior of customers.

\section{DISCUSSION}

The study examined the relationship between e-marketing and consumer buying behavior using both postgraduate and undergraduate students at Osun State University. Out of the four dimensions of e-marketing tested in this study, three hypotheses were significant with consumer buying behavior. Specifically, email marketing, mobile marketing, and e-advertising are significant with consumer buying behavior. In marketing practices, several scholars have examined the impact of e-marketing as part of interactive technologies. For instance, El-Gohary (2012) examined e-marketing and presented a model of e-marketing based on five important factors with the relationship on the business to the business model (B2B) in Egypt and such model was extended and validated from prior models (Technology Acceptance Model TAM and Innovation Diffusion Theory IDT). Also, Coviello et al., (2001) employed e-marketing as 5th essential element of contemporary marketing practices. Likewise, Waheed and Jianhua (2018), examined e-marketing and presented a model of e-marketing based on five important elements with the relationship on the business to customer model (B2C) in China. Thus, this study extends the e-marketing model of Waheed and Jianhua (2018) with an in-depth and comprehensive analysis of each four dimensions towards consumer buying behavior based on the relationship from a business to customer (B2C) relationship. Therefore, it has become a priority for management to realize how to win over the consumers in the competitive environment today, to develop an effective and creative marketing strategy that undergo the process to understand the prevailing drift among consumers before broadcast any information.

\section{CONCLUSION AND RECOMENDATION}

This research study has presented an overview and relevant discussions on some of the main factors in e-marketing that influence consumer buying behavior for University students in Nigeria, particularly in Osun State where the study was conducted. The result of this study indicated that e-marketing is a flourishing tactic that can be used to replace conventional marketing. That is, the promotion of products/services using electronic marketing can contribute to the dynamic influence in marketing communication to reinforce consumer buying behavior trends. Most especially, e-mail marketing has been a prominent tool for promotional activities bearing positive consequences. Hence, marketers are encouraged to consider diverse observations during the implementation of the e-marketing campaign. Also, marketing communication through mobile devices may perform a significant role were such a large market is mobile users. Thus, the marketers suggested that the selection of contents such as video, audio, graphics, images, and text has an immense role to strengthen buying tendencies via the diverse feature of mobile devices like SMS, WAP, MMS, Bluetooth, and other mobile apps. Another area is e-advertising which is alternatively called internet marketing has been acknowledged as an excellent method of network technologies. The advertisers are encouraged to use e-advertising where such strategies support to broadcast the messages in a wider manner via network technologies like social media ads; digital ads; web banners among others. Thus, it is a strategic decision to employ an effective channel of e-advertising within the available resource of the company to prompt the buying behavior of the target audience.

Finally, this study is limited the data collection to the students who are using online transactions in the Universities in Osun State, therefore, the study needed to consider other sectors and other regions for the generalization of the study. Besides, replication of further empirical study toward remainder areas along with different sample size may help to validate the findings of such thriving technologies and innovation in the future studies, specifically, proposed directions for both practitioners and academicians in this study area. Finally, this study considers the business 
to customer relationship, hence, a further research study in Nigeria may consider business to business and business to government relationship to have more evidence across the world.

\section{REFERENCES}

Adebayo, P. O., Osanyinlusi, G. E., \&Adekeye, A. O. (2017). Impact of E-payment system on buying behaviour: evidence from retail outlets in Ilorin metropolis, Nigeria. International Journal of Research in Arts and Social Sciences, 9(2), 137-152.

Agarwal, S. (2019). Impact of Demonetization on Consumer's Buying Behaviour Towards Online Shopping. In Proceedings of 10th International Conference on Digital Strategies for Organizational Success.

Agyare, M. (2019). Influence of Electronic Advertising on Consumers Purchasing Decisions of Alcoholic Beverages within the Accra Metropolis (Doctoral dissertation, University of Cape Coast).

Ajiboye, A. F., Ogunrinade, R., \& O Ayanleke, S. (2018). E-Marketing and Organizational Performance: A Study of Five Manufacturing Companies in Oyo State, Nigeria. South Asian Journal of Social Studies and Economics, 1-9.

Arifin, Z. \&Frmanzah, B. (2015). The effect of dynamic capability to technology adoption and its determinant factors for improving firm's performance; toward a conceptual model. procedia - Social and Behavioral Sciences, 2(20), 786-796.

Ashwini.N, \&Manjula, R. (2016). An empirical study on consumers' perception towards onlineshopping. International journal of management and commerce innovations, 11031110.

Aslam, B., \&Karjaluoto, H. (2017). Digital advertising around paid spaces, E-advertising industry's revenue engine: A review and research agenda. Telematics and Informatics, 34(8), 1650-1662.

Asnawi, A., Awang, Z., Afthanorhan, A., Mohamad, M., \& Karim, F. (2019). The influence of hospital image and service quality on patients' satisfaction and loyalty. Management Science Letters, 9(6), 911-920. https://doi.org/10.5267/j.msl.2019.2.011

Bauer, H.H., Reichardt, T., Barnes, S.J. and Neumann, M.M. (2005), "Driving consumer acceptance of mobile marketing: a theoretical framework and empirical study", Journal of Electronic Commerce Research, Vol. 6 No. 3, pp. 181-192.

Bawm, Z.L. and Nath, R.P.D. (2014), "A conceptual model for effective email marketing", 2014 17th International Conference on Computer and Information Technology (ICCIT), IEEE, Dhaka, December 22-23.

Bhakar, S., Bhakar, S., \&Kushwaha, K. (2019). The Effectiveness of E-Advertisement towards Customer Purchase Intention: Indian Perspective. In Proceedings of 10th International Conference on Digital Strategies for Organizational Success.

Brodie, R.J., Winklhofer, H., Coviello, N.E. and Johnston, W.J. (2007), "Is e-marketing coming of age? An examination of the penetration of e-marketing and firm performance", Journal of Interactive Marketing, Vol. 21 No. 1, pp. 2-21.

Cases, A.-S., Fournier, C., Dubois, P.-L. and Tanner, J.F. (2010), "Web site spill over to email campaigns: the role of privacy, trust and shoppers' attitudes", Journal of Business Research, Vol. 63 No. 9, pp. 993-999.

Chandoriya, K. R. (2016). Changing Buying Perception towards Branded Durable Products Through E-advertising. Pacific Business Review International, 8(11), 40-43.

Chang, H.H., Wang, Y.-H. and Yang, W.-Y. (2009), "The impact of e-service quality, customer satisfaction and loyalty on e-marketing: moderating effect of perceived value", Total Quality Management, Vol. 20 No. 4, pp. 423-443.

Chin, L. P., \& Ahmad, Z. A. (2015). Perceived enjoyment and Malaysian consumers' intention to use a single platform e-payment. In SHS Web of Conferences (Vol. 18, p. 01009). EDP Sciences.

Constantinides, E. (2004). Influencing the online consumer's behavior: the Web experience. Internet research, vol. 14, pp. 111- 126, 2004.

Coviello, N., Milley, R., and Milley, B. (2001). Understanding IT enabled interactivity in contemporary marketing. Journal of interactive marketing, vol. 15, pp. 18-33, 2001. 
Deshwal, P. (2016). Online advertising and its impact on consumer behavior. International Journal of Applied Research, 2(2), 200-204.

Digital Empowerment \& Wealth Creation (2017). Mobile marketing. [Online] Available at: http://dewinitiatives.com/mobile-marketing.

Edoumiekumo, S. (2017). The Impact Of Globalization On The Nigerian Financial Sector (Doctoral dissertation).

El-Gohary, H. (2012). Factors affecting E-Marketing adoption and implementation in tourism firms: An empirical investigation of Egyptian small tourism organizations. Tourism management, vol. 33, pp. 1256-1269, 2012.

El-Gohary, M. R., and Kotabe, M. (2001). Marketing Management, South, Western College Publishing, USA, 2001.

Evans, J. R., \&Mathur, A. (2005). The value of online surveys. Internet research.

Farley, A., Day, G. S. and Bens, K. J. (2005). Capitalizing on the internet opportunity. Journal of Business \& Industrial Marketing, vol. 20, pp. 160-168, 2005.

George, C. C., \& Education, B. E. U. (2019). Influence of Advertising on the Sale of Shopping Goods in Bayelsa State (Doctoral dissertation, Thesis (M. Sc.)-University of Nigeria, Nsukka, 2010.

Gerrikagoitia, J. K., Castander, I., Rebón, F., \&Alzua-Sorzabal, A. (2015). New trends of Intelligent E-Marketing based on Web Mining for e-shops. Procedia-Social and Behavioral Sciences, 175(1), 75-83.

Griffis, S.E., Rao, S., Goldsby, T. J. \&Niranjan, T.T. (2003). The customer consequences of returns in online retailing: An empirical analysis. Journal of operations management, 30, 282-294.

Hamdi, R., \&Khemakhem, R. (2019a). Online Advertising and Consumer Behavior in Tunisia: Identification of New Mediating and Moderating Variables. IUP Journal of Marketing Management, 18(4).

Hooda, S., \& Aggarwal, S. (2012). Consumer behaviour towards e-marketing: A study of Jaipur consumers. Researchers World, 3(2 Part 2), 107.

Kalu, A. O., Nto, C. P., \&Nwadighoha, E. E. (2017). Environmental Forces as Catalysts in Electronic Marketing, the 21st Century Trends in Nigeria. Kuwait Chapter of Arabian Journal of Business and Management Review, 33(81), 1-11.

Kotabe, P. (2009). Marketing management: A south Asian perspective: Pearson Education India, 2009.

Kotabe, R. J., Kotabe, H., Kotabe, N. E. and Johnston,W. J. (2007). Is e-marketing coming of age? An examination of the penetration of e-marketing and firm performance. Journal of interactive marketing, vol. 21, pp. 2-21, 2007.

Kotler, P. \& Armstrong, G. (2012), Principles of Marketing, (9th Ed), New Jersey: Prentice Hall Inc.

Lee, K.Y., Lee, M. and Kim, K. (2017), “Are smartphones helpful? An empirical investigation of the role of smartphones in users' role performance", International Journal of Mobile Communications, Vol. 15 No. 2, pp. 119-143.

Loane, S., Loane, R. B., and Bell, J. (2004). The internationalization of Internet enabled entrepreneurial firms: evidence from Europe and North America. Canadian Journal of Administrative Sciences/Revue Canadienne des Sciences de l'Administration, vol. 21, pp. 79-96, 2004.

McCloskey, W. (2006), "Retail white paper", Email Data Source, New York, NY

Mullen, J. and Daniels, D. (2011), Email Marketing: An Hour a Day, John Wiley \& Sons, IN

Nwokah, N. G., \&Irimagha, B. B. (2017). E-Marketing Orientation and Social Media Implementation in the Banking Industry in Nigeria. iBusiness, 9(4), 111-133.

Ogundele, O. J. K., Akingbade, W. A., Saka, R. O., Elegunde, A. F., \&Aliu, A. A. (2013). Marketing practice of small and medium enterprises (SMEs): Perspective from a developing country. Mediterranean Journal of social sciences, 4(3), 243.

Pavlov, O.V., Melville, N. and Plice, R.K. (2008), "Toward a sustainable email marketing infrastructure", Journal of Business Research, Vol. 61 No. 11, pp. 1191-1199.

Persaud, A. and Azhar, I. (2012), "Innovative mobile marketing via smartphones: are consumers ready?”, Marketing Intelligence \& Planning, Vol. 30 No. 4, pp. 418-443. 
Princewell, N. A., Anuforo, R. (2013). Shifting policy paradigm from cash-based economy to Cashless economy the Nigeria experience. Afro Aslan Journal of Social Sciences, 4(4).

Raza, I., \&Awang, Z. (2020). Knowledge sharing in multicultural organizations: evidence from Pakistan. Higher Education, Skills and Work-Based Learning.

Saunders, C., Gebelt, M. \& Hu, Q. (2012). Achieving success in information systems outsourcing, California Management Review (39:2), 63-79.

Sheikh, A. A., Shahzad, A., \& Ku Ishak, A. (2017). The growth of e-marketing in business-tobusiness Industry and its effect on the performance of businesses in Pakistan: Marketing Success. International and Multidisciplinary Journal of Social Sciences, 6(2), 178-214

Smutkupt, P., Krairit, D. and Esichaikul, V. (2010), "Mobile marketing: implications for marketing strategies", International Journal of Mobile Marketing, Vol. 5 No. 2, pp. 126139.

Sterne, J. and Priore, A. (2000), Email Marketing: Using Email to Reach Your Target Audience and Build Customer Relationships, John Wiley \& Sons, Inc., New York, NY.

Tomlinson, R. (2009), The First Network Email, available at: www.raytheon.com/news/rtnwcm/groups/ public/documents/content/rtn12_tomlinson_email.pdf (accessed March 10, 2017).

Waheed, A., \& Jianhua, Y. (2018). Achieving consumers' attention through emerging technologies. Baltic journal of management.

Waheed, A., Yang, J., \&Rafique, K. (2017). Understanding the effect of E-marketing (eM) on online consumer buying behavior. In Proceedings of the 2017 International Conference on Management Engineering, Software Engineering and Service Sciences (pp. 163-167).

Wu S, Wei S and Chen T (2008) Influential factors and relational structure of Internet banner advertising in the tourism industry. Tourism Manag. 29 (2): 221-236.

Xena, P., \&Rahadi, R. A. (2019). Adoption of e-payment to support small medium enterprise payment system: A conceptualized model. International Journal of Accounting, 4(18), 3241.

Zeithaml, V. A. \& Gilly, M.C. (1987) Characteristics affecting the acceptance of retailing technologies: a comparison of elderly 